\title{
Article
}

\section{The Sphere of Critical Thinking in a Post-Epistemic World}

\author{
STEVE FULLER University of Durham
}

Key Words: Social epistemology; cognitive norm; criticism; Rousseau; Feyerabend; naturalized epistemology; democracy; science; social psychology; expertise; politics; accountability.

Abstract: Just as political theorists have long argued that democracy is viable only in communities of certain sizes and shapes, perhaps epistemologists should also entertain the idea that knowledge is possible only within certain social parameters-ones which today's world may have exceeded. This is what 1 mean by the "postepistemic" society. I understand an "epistemic society" in Popperian terms as an environment that fosters the spirit of conjectures and refutations. After castigating analytic philosophers for their failure to see this point, I show how Rousseau and Feyerabend occupy analogous positions as critics of, respectively, the nation-state and Big Science. Rather than endorsing the disestablishment of the state, however, I offer a proposal for reinjecting the critical attitude into Big Science. It involves heightening the sporting character of scientific disputes, perhaps even to the point of enabling the public to bet on their outcomes.

Over the past five years, I have been developing a way to reconcile empirical social scientific studies of the knowledge enterprise and normative philosophical claims about the nature of knowledge. I call this synthetic project social epistemology (Fuller 1988, 1989). One conclusion that my critics have urged upon me is that the very existence of a knowledge enterprise-"science," for short-should not be taken for granted. Of course, in both academic and lay discourse, behavior is frequently explained in terms of one's possession of knowledge-related things, or "epistemic entities." Among the things possessed include beliefs, reasons, intelligence, cognitive processes, (access to) information, disciplinary or technical training, theoretical assumptions, worldviews, and lines of thought. Although it is easy to imagine contexts in which one or more of these entities might be used to account for what someone has done, it is difficult to see how all of them could be accommodated within a single conceptual framework. That alone would seem to demonstrate the extent to which appeals to epistemic entities are typically made without much thought to their appropriateness or reliability. In a more systematic vein, social psychologists have begun to challenge the power of beliefs and reasons to explain people's behavior, including one's own behavior (cf. Nisbett \& Wilson 1977, Hewstone 1989). We need to push this challenge still further, encompassing tests of the other entities mentioned above. In this paper, I will explore some interesting political possibilities that are opened up by the "end of knowledge."

What is at stake here? A useful way to think about the stakes is to consider what would follow from a demonstration that all of our appeals to epistemic entities commit a version of what social psychologists call the "fundamental attribution error" (Ross 1977). In other words, suppose it were shown that human behavior is more a function of one's situation than of whatever "knowledge" one brings to the situation. Consider the sorts of studies that would be 
relevant to such a finding. For example, social psychologists may fail to find significant differences between the decisionmaking patterns of economists and noneconomists; in fact, manipulating the decision task itself may be a more reliable way of changing the behavior of both groups than providing additional training in economics. Would it any longer make sense to defer to someone's judgment because of the economic knowledge they possess? What would become of education in economics? What would "credentials" and "expertise" in economics mean under these circumstances? More generally, how can someone be held accountable for their actions if claims to knowledge do not seem to make an empirical difference to their behavior? Indeed, if all discipline-based training is implicated by this finding, what would be the status of the very social psychological research that had established it?

These are the sorts of probes that a truly empirical study of knowledge needs to make of epistemic entities. Just as our unreflective attitudes toward nature and society need to be subject to scientific scrutiny, so too do our unreflective attitudes toward science itself. Many of these "reflexive" probes have already been conducted by self-styled "constructivists"ethnomethodological sociologists (e.g. Knorr-Cetina \& Cicourel 1981, Coulter 1983), social psychologists (e.g. Gergen \& Gergen 1982, Gergen 1985), and sociologists of science (Gilbert \& Mulkay 1984, Woolgar 1988, Mulkay 1990)-who have studied the situational variability of knowledge-talk in ordinary and scientific settings. There is a tendency in this literature to marvel at the virtuosity of human adaptive capacities that this phenomenon seems to imply. My suspicion, however, is that "situational variability" will turn out to be a euphemism for the fact that epistemic entities explain very little without an embar-rassingly large number of ad hoc background assumptions. The overall impression I have, then, is that, once systematized, our current knowledge-talk will more closely resemble Ptolemaic astronomy than Newtonian mechanics - in both its restricted utility and its ultimate dispensability.

\section{The Difficulties with Naturalizing Epistemology: A Diagnosis}

At this point, let me confront one obvious objection. I have assumed that if epistemic entities explain anything-or, for that matter, if there are such entities at all-then they must stand in some systematic relation to a particular class of social phenomena. Yet, this assumption would seem to beg the question against the significance of our knowledge-talk, the selfcontained character of which is supposed to show that the sorts of pursuits alternatively deemed "rational," "cognitive," "epistemic," or "scientific" are governed by standards internally defined by such talk, standards which are sustainable under a variety of social arrangements. Thus, Karl Popper's adaptation of Clausewitz's famous saying - that modern science is Socratic dialectic continued by other means-reflects the widespread belief among philosophers and scientists that, if one is willing and able to rise to the level of critical scrutiny demanded of scientific inquiry, then it does not matter whether one is tackling problems in the lab or in the marketplace. On such a view, there is no "in principle" reason why knowledge could not be reliably produced by individuals as well as groups, by large groups as well as small, by groups whose members are concentrated or dispersed in time and space. I want to argue not only that this view is based on wishful thinking but that those who have managed to see this point have yet to come fully to grips with its implications.

Philosophers of science are inveterate Hegelians. Like Hegel, they believe that the knowledge enterprise has only one spatiotemporal boundary, namely, an origin. 
Throughout the nineteenth and most of the twentieth century, this origin was commonly located-as my previous remarks about Popper suggested-in 4th century $\mathrm{BC}$ Athens. In recent years, as the motor of scientific progress has become more closely identified with experiment than with theory, the origin has been moved up to 17th century Europe. Some philosophers, notably Charles Sanders Peirce and Nicholas Rescher (1978, 1979, 1984), have entertained the possibility that the knowledge enterprise may come to end-not because we solve all the mysteries of the universe, but because it is no longer worth our while to continue doing so. The rate of return on investment in scientific research simply becomes too small. There is a certain Hegelian justice in this view, too, in that what would happen is that the calculative rationality so characteristic of the knowledge enterprise throughout its historical career will eventually put itself out of business by performing a meta-calculation of its own utility. Yet, curiously, this view of a possible termination of scientific inquiry is often presented as externally imposed, in the sense that it seems to turn on letting other pragmatic concerns of the human condition trump the pursuit of knowledge for its own sake. My point here is not to dispute this interpretation of what Peirce and Rescher have proposed, but rather to suggest that there is another sense in which the knowledge enterprise may terminate "from within," and indeed, may have already done so, though our ordinarily promiscuous appeal to epistemic entities continues to obscure the fact.

Again like Hegel, philosophers of science-especially those who hold on to the notion of scientific progress-take for granted that science improves with ever more participants over ever longer periods of time. In particular, it is supposed that the principles of experimental inquiry that were first instituted by a small group of English gentlemen in the 17th century (cf. Shapin 1988) were gradually refined as the opportunities for their deployment were expanded. However, bigger science makes for better science only if, say, experimental inquiry is not, in the economists' words, scale-sensitive. A scale-sensitive enterprise is one which turns into some other enterprise, often one whose dominant functions are quite different from those of the original one, once its dimensions have been significantly extended (cf. Clark 1985, ch. 4). Hegelians and Marxists should recognize the metaphysical version of this principle, namely, "the transformation of quantity into quality." In more down-to-earth terms, the relevant transformation occurs when the activity in question is no longer governable by its original set of principles. One piece of evidence that strongly suggests that science has outgrown its original principles is the difficulties that "naturalized" epistemologists and philosophers of science have faced in trying to situate traditional cognitive norms in an empirically adequate account of today's knowledge enterprises (Faust 1984; Fuller 1989, ch. 2; Fuller 1992a,b).

Virtually every cognitive norm that philosophers have advanced - be it deductive, inductive, or abductive-has a pedigree that reaches back at least to Newton, and often to Aristotle. That is to say, the norms harken back to a time when the knowledge enterprise was conducted on a much smaller scale than it currently is. As continuing testimony to the Cartesian legacy in modern philosophy, naturalized philosophers have typically looked for these norms in the minds of individual knowers. But in the face of strong psychological evidence to the contrary, philosophers have been forced either to relocate the norms in mental realms beyond the reach of experimentation or to offer the vague hope that some training in methodology will remedy the demonstrated "deficiencies" (cf. Cohen 1981). Dissatisfied with these two strategies, some philosophers have pursued the Peirce-Popper route of arguing that cognitive norms really govern group processes, 
but little effort has been devoted to determining which sorts of norms have a chance of governing which sorts of groups. Instead, this literature tends to be populated with abstract models inspired by neoclassical economics which, whatever their specifics, presume that the knowledge enterprise is improved by increasing the number of information processing nodes in the network (cf. Kitcher 1990, Goldman \& Shaked 1991). And, as if to compound the problem, still other philosophers have suggested that computers might make better nodes than humans (Thagard 1988, Slezak 1989), though it remains to be seen whether computers are welcomed into the guild of scientists or the definition of scientific reasoning is altered so as to exclude computers once again (cf. Dolby \& Cherry 1989, Collins 1990). In either case, it is clear that the knowledge enterprise has been cut loose from its traditional moorings. The question before us, then, is this: Has the nature of the knowledge enterprise fundamentally changed as a result of its dimensions having exceeded certain limits (cf. Price 1964)? Is "Big Science" a contradiction in terms?

\section{The Ungovernability of Big Democracy and Big Science: Of Rousseau and Feyerabend}

An analogue of the above question is familiar from political theory. Rousseau's worries about the possibility of democracy in the modern world will provide a helpful departure for thinking about the question I am raising. Rousseau is famous for confronting the scale-sensitive character of democratic regimes. A true believer in the classical paradigm of democracy, the Athenian polis, Rousseau argued that a democracy lost its "governing principle" once it reached a size that enabled the formation of conflicting interests. His point was that democracy, in. the strict sense, only flourished in relatively small, homo- geneous societies, whose members respected each other as equals and were thus willing to abide by a group consensus. Given the size and complexity of 18 th century Europe, Rousseau saw only two options for government: tyranny or democracy. Tyranny prevailed, if nation-states retained their current dimensions. Democracy prevailed, if nation-states were disestablished, and people divided up into small self-governing units. I would like to suggest that Paul Feyerabend $(1975,1979)$ presents us with a set of Rousseauian options vis-a-vis the current state of the knowledge enterprise. But pace both Rousseau and Feyerabend, I believe we need to explore the option that they reject.

Feyerabend is basically a scalesensitive Popperian, one who believes that science in the spirit of "conjectures and refutations" can only exist in social milieus where people can freely and publicly cross-examine each other's claims, and where claimants can receive prompt and reliable feedback, so that they can propose better claims in the future. Social psychologists would see what I am describing here as an instance of "brainstorming," which typically works in small, intimate settings where people are emotionally prepared to undergo intense and immediate scrutiny. Philosophy meetings often have this character, although they are hardly the occasions that inspire confidence in the idea that knowledge has "progressed." There is evidence that brainstorming also occurs in some research teams in the laboratory sciences, though probably more so in corporate settings than in university ones. In any case, with the exception of a few staged public events of dialectical warfare and a nostalgic view of graduate seminars, conjectures and-especially-refutations are confined to the backrooms of Big Science. This point is often obscured because the free exchange of information that characterizes scientific inquiry today is mistakenly equated with the promotion of the critical attitude that philosophers as diverse as 
Mill, Dewey, and Popper have attributed to a fully functioning knowledge enterprise. With the free exchange of information has come an information explosion, an important consequence of which is that scientists are more likely now to simply ignore the sort of work that in a more Popperian world would be subject to explicit refutation. As Bourdieu (1975) and Latour \& Woolgar (1979) have observed, scientists work hard in the literature review sections of their articles to construct a framework within which their research will appear credible. And here, "credibility" is measured by a scientist's ability to get other scientists interested, and ultimately engaged, in her own projects. If she succeeds, she has avoided oblivion - at least for a little while.

Given the dimensions of Big Science, credibility needs to be earned at every turn, not because today's scientists are less competent than earlier ones, but because there are too many scientists of prima facie equal competence. When the scientific enterprise was smaller, it was reasonable to presume that whatever one wrote would be subject to critical scrutiny by the relevant disciplinary community, whose members would be on the lookout for new work in their area. It is no longer possible for the scientist to take her audience for granted in that manner. To gain credibility, she must often embed her research in so many different technical contexts at once-theoretical, methodological, experimental-that it would be impractical for a prospective reader to approach her text without already expecting to incorporate it in her own research. The style manuals of most science joumals contribute to this effect by requiring that authors frame their discussions of "theory," "method," and "data" as detachable modules-ostensibly, in an effort to make their articles usable by a wide range of scientific readers, most of whom will be interested in some sections but not all (Bazerman 1988). Indeed, research articles are becoming pure boilerplate (cf. McCloskey 1987). Moreover, the high ex- pense and low payoff (in terms of publication possibilities) of redoing experiments and reanalyzing data produced by other scientists are well-known. None of these developments bodes well for the future of the critical attitude in science.

Perhaps the closest that scientists nowadays come to refuting one another is by offering alternative theories for roughly the same range of phenomena. But, of course, providing another viewpoint falls far short of formal criticism, especially in terms of giving one a clear basis for changing one's behavior. At best, it serves to signal dissent in the scientific ranks. Finally, even in the few cases in which a piece of research is formally criticized, the effectiveness of the criticism as negative feedback is often undermined by delays in publication and distribution. Given the ever quickening pace of Big Science, even if we assume that a piece of criticism is unequivocal in its consequences for a line of research (a big if, in light of the underdetermination of theory choice by evidence), considerable bodies of work incorporating faulty research may be corrupted by the time the criticism comes out.

As I said, Feyerabend is epistemology's answer to Rousseau. He too is enamored of the polis-but this time as the model of critical inquiry. And, as critical inquiry gets shunted to the periphery of Big Science, he poses the following Rousseauian dilemma: either admit that the human condition has outgrown the possibility of critical inquiry or reclaim critical inquiry by scaling down Big Science. Again, tyranny or democracy. Like Rousseau, Feyerabend clearly opts for the latter, which he pursues in the spirit of showing that science as it exists today is primarily not a knowledge enterprise. Aside from the marginalization of criticism discussed above, the evidence for this side of Feyerabend's argument is easy to come by.

Put most generally, the production of both basic and applied research and the production of what the sociologist $\mathrm{C}$. 
Wright Mills called "the military-industrial complex" constitute increasingly larger portions of each other's activities. For example, until quite recently, the US Defense Department spent more of its money on research, and more money for research was coming from the Defense Department than from anywhere else in the government. At the very least, this symbiosis seriously altered the terms in which-and to whom-research can be held accountable (cf. Noble 1984). I do not deny that "methodological soundness" might figure prominently in, say, military criteria for evaluating radar detection devices. But that only shows the extent to which the military regards philosophically familiar standards as instrumental to its ends. (It remains an open question whether they are right! [cf. MacKenzie 1990, ch. 7]) So much the better for science funding that the military can take cover under philosophical rubrics. But to what extent, if any, is research any longer evaluated as products of inquiry? What follows are three philosophically inspired reasons for thinking that the extent is rather small, and, indeed, were we seriously interested in evaluating research as products of inquiry, we might need to return to Little Science. These reasons, though offered in the spirit of Feyerabend's radicalism, should be seen as motivated by a fairly traditional understanding of science as aiming to represent the structure of reality.

(1) Nothing in the formulation of a theory dictates the means by which it should be tested. Historians and sociologists of science have no trouble showing the conventions that have had to be instituted in order for certain theoretical practices to be related to particular data gathering techniques and standards of evaluation. Only institutional inertia and historical amnesia make these conventional connections seem, in some way, "necessary." In that case, why must advanced physical theories be tested on ever more expensive equipment? The only clear function that this trend serves is to reinforce a certain nexus of scientific, commercial, and political interests. The interests of inquiry might, by contrast, be better served by considering alternative techniques for resolving theoretical disputes. Without endorsing any specific proposals here, one may find precedent for such considerations in the controversies surrounding the Critical Legal Studies movement in American jurisprudence, part of the agenda of which is to construct institutions of dispute resolution that destabilize, rather than reproduce, existing power structures (Unger 1986). If inquiry aims at The Truth, then different combinations of interests should stumble upon the same findings. However, if only a particular combination can make all the relevant findings, then one may reasonably ask - as has been recently asked of sociology itself (Tumer \& Turner 1990)-whether those findings are an artifact of that scientificeconomic-political combination.

(2) If a strong distinction can be drawn between the social processes of knowledge production and the objective products that result from those process$\mathrm{es}$, then it is not at all clear that the progress of science need be impeded by diminishing the scale of its production, say, by eliminating scientific jobs and deterring people from entering scientific careers. After all, what may be best for science may turn out not to be so good for scientists. However, the realist should not fear that a decline in scientific employment would necessar. ily lead to a concentration of scientific activity in the hands of predictably elite individuals from elite institutions. What may be best for promoting intelligence in the individual may turn out not to be so good for promoting knowledge in the collective. In other words, it may be that knowledge production is optimized by maximizing the spread of competencies, and maybe even the spread of intelligence levels. The latter spread may be needed to counteract the tendency of quick-witted people to find holes in theories all too easily, and hence to reject them prematurely. Indeed, the natural sciences might have suffered the fate of philosophy, if it employed a surfeit of the super-intelligent? 
(3) The plausibility of the realist position may actually be increased by admitting that the highly specialized, fragmentary character of knowledge in the world of Big Science constitutes an epistemic step backward. At least, the realist would then be able to argue that her position is not parasitic on a selfvindicating Whig history of science that presumes, without argument, that today's science is the closest that we have yet gotten to The Truth. General cultural history offers many precedents for this "Silver Age" mentality. Typically, the period of decline is cast as one of bewildering complexity, by contrast with the unity and simplicity of the earlier "Golden Age" (cf. Fuller \& Gorman 1987). For example, if we suppose that, at the limit of inquiry, scientific theories correspond to the structure of reality, then we might say that at a certain point in history-say, when physics became committed to searching for the ultimate micro-constituents of matter in highly artificial laboratory settings-theoretical elaboration became more finely grained than the structure of reality itself. Scientists began to make distinctions in their language that did not make an empirical difference-that is, without the aid of the manufactured environment in the lab. If this is an apt story of the twentieth century, then there is a sense in which the dimensions of science exceeded the limits of "natural" reality. Indeed, such was the subtext of Feyerabend's doctoral dissertation on Niels Bohr.

\section{Science in a World without Knowledge}

Despite its relative popularity, the nostalgic side of Feyerabend is not what ultimately interests me. Scaling down science to a size that makes it accountable to the community in which it is practiced would clearly enable more people to be directly involved in the conduct of inquiry, but it would continue to obscure the impact that even such a "little" science has on those living outside the community. In that sense, unless special provisions are made, Little Science is no different from Big Science in holding scientists responsible only for consequences that affect those to whom they are directly accountable. As a result, I want to pursue the other side of Feyerabend's position, namely, the side that admits that science no longer exists-or, to put the thesis more carefully, the markets in which scientists currently conduct their business have expanded to the point of rendering obsolete the treatment of certain artifacts and skills as knowledge-bearing. Thus, descriptions of scientific activity that make reference to epistemic entities will be unreliable predictors of that activity. If this side of Feyerabend's argument holds, then philosophers have yet again been fooled into thinking that the persistence of a certain kind of talk-in this case, epistemic talk-reflects the persistence of a certain underlying reality, namely, the knowledge enterprise. But how would such a ruse have worked? Consider the following three tendencies in philosophical discussions about science:

(1) While philosophers now give some at tention to the social conditions of knowledge production, they still assess these conditions solely in terms of their specifically "epistemic" consequences, rather than in terms of their more general impacts on society, which, of course, together constitute the social conditions for subsequent knowledge production. As a result, there is some talk about which social arrangements foster or retard knowledge growth, but the full dimensions of Big Sciencewho and what ends up being enveloped in its sustained pursuit - remain obscured. This situation is largely an artifact of the subdivision between ethics and epistemology within professional philosophy in the Anglo-American world, which fosters the illusion that a clear distinction can be drawn between the morally and epistemically relevant consequences of a given course of action.

(2) Philosophers employ a curious doublethink about the "autonomy" of modern science, which leads them to assert 
that, say, physics has become more autonomous in its research trajectory precisely during the period that it has been most subject to government interference and direction. This tension is often managed by drawing a sharp distinction between what is "internal" and "external" to science, such that the latter category contains, say, funding, over which practicing scientists have little direct control. Under duress, most philosophers would concede that funding decisions play a preponderant role in the direction that scientific research takes. Yet, they would continue to stress that these economic matters are not constitutive of science "as such."

(3) Finally, philosophers simply fail to take seriously the fact that scientists today spend an increasing amount of time on entrepreneurial, managerial, and accounting tasks at the expense of "research" in the traditional sense of doing experiments, consulting the literature, and the like (cf. Elzkowitz 1989). Moreover, this is not simply a matter of scientists being overworked, but more a matter of their coming to view the traditionally "scientific" aspects of their work-especially reasoning with hypotheses and writing for peers-as routinizable, perhaps ultimately computerizable. The seat of "real" creativity would seem to lie in the tactics one uses to sustain funding and earn credibility, especially given the growing number of competitors who are trying to do exactly the same thing. Any organizational sociologist would conclude from this that the character of scientific work has changed to the point that the scientist's primary function is now a sophisticated form of publicity-seeking and record-keeping that enable others-both scientists and nonscientists - to legitimate or delegitimate certain courses of action. In fact, not only are funding agencies fully aware of this shift in the scientist's work habits, they often actively encourage it (cf. Mukerji 1990).

If the classical search for knowledge has, indeed, come to an end, how did it happen, and, more importantly, what should we who believe in a critical epistemic attitude do about it? An historian interested in this question would want to look at the roots of two developments, (1) Fewer people have become eligible to dispute a given knowledge claim as the qualifications needed for entering the forum have increased. These qualifications include not only the training needed to read and write in the relevant journals, but also the more elusive knowledge needed for turning archival and technical resources to one's advantage. (2) At the same time, as the eligibility for disputing knowledge claims has come to be restricted, those claims have come to play a greater role in explaining and legitimating policies, actions, and events; hence, the increased government reliance on science to underwrite its activities (Mukerji 1990, ch, 2). Together, these two developments point to the long term tendency of science becoming a more acute instrument of social power, as its sphere of accountability diminishes. The overarching implications of this political asymmetry are clear: Science is producing proportionally fewer peoplenot necessarily the scientists themselves but those with access to science-able to exert proportionally greater impact on the lives of others. And here, "impact" should be measured in terms of not simply the capacity for destruction and dislocation, but also the capacity for pauperizationthrough the money that people involuntarily and unreflectively contribute to research in the form of taxes.

Once again, the philosopher may return by saying that these developments are not "necessary" or "essential" to science. But, as the checkered track record of naturalized epistemology suggests, the various norms that philosophers have proposed as integral to inquiry turn out to be remarkably hard to find in practice. Philosophers of a postmodernist sensibility, such as Richard Rorty (1988), conclude from this that science simply has no essence. They say that "science" is a genre, a way of telling the story of Western culture that uses 
terms like "rationality," "method," "truth," as elements of the plot structure. Without denying the importance of such a narrative in normalizing the transition between "Little" and "Big" Science, the postmodernist's complete disregard for essentialist talk makes her unable to distinguish two conceptions of the history of science that are crucial for the argument I want to make: namely, between (a) a loose collection of practices whose narrative relevance to one another-and that alone-makes them sciences and (b) a real process whereby one practice evolves or mutates into another practice that turns out to be better adapted to the new social environment. The directed and perhaps even irreversible character of this second sense of history-that the bigness of the world has forced science to outgrow traditional epistemic conceptions-encourages us to think of science as having acquired a new set of governing principles, a "new essence," so to speak. To cite only the most vivid case in point, the pursuit of high-energy physics has become so expensive that nation-states and large corporations are the only institutions in which capital is sufficiently concentrated to enable physicists to work in a relatively uninterrupted manner. Should these centers of capital ever become radically dispersed, physics would have a hard time continuing in its present form (cf. Kevles 1987, esp. preface). In short, science depends for its livelihood on the militaryindustrial complex, just as much as the latter depends on the former for its legitimation. A case of this sort is about as close as one ever gets to demonstrating that something is "essential" for something else.

At this point, I want to discourage one line of advice that philosophers in the liberal tradition have held to be sufficient to empower peuple in this era of Big Science, namely, "education," especially when this term is taken to imply the elimination of epistemic privilege simply by distributing the crucial elements of the privileged class' body of knowledge or set of reason- ing skills to society at large. For all its nobility, this proposal mistakenly assumes that the locus of epistemic privilege lies in the sort of intellectual qualities that, say, scientists have but ordinary people lack, rather than in the sort of access to intellectually empowering tools that one group has but the other lacks. One of the more frustrating findings that naturalized epistemologists have had to face is that very little seems to distinguish the minds of scientists from those of nonscientists. The former are no less susceptible to bias and error than the latter, even with the "right" training in formal logic, statistical methodology, and experimental design. However, scientists are organized in a way that enables the whole to greatly exceed the sum of the parts. This organization can be described in both structural and functional terms.

Structurally, science consists of distinctive networks of disciplinary languages, shared technologies, and professional forums. However, these networks function-as a matter of consequence, if not of design - so as to produce a certain distribution of power in society. In particular, the structure of science is permeable to state agencies and corporations. They can make a strategic difference to the direction that the knowledge enterprise takes by adding or withholding support. This, in turn, serves to enhance the power of these institutions at the expense of other groups in society. By contrast, ordinary citizens, who are typically on the receiving end of a "knowledge transfer," encounter science as a fait accompli, a "black box" in Latour's (1987) sense, over which they exert control only in determining the "applicability" of a particular scientific product to the place where they live. And even here, the degree of control can be overestimated, since often the products of science that would most benefit people in a given locale are not made available to them, while economic and political pressure may be placed on the very same people to accept other products of science that they would normally not 
have any use for. The fruits of cutting-edge medical research fall into the former category, while nuclear and chemical plants often seem to fall under the latter. However, the relative power that government and business have over ordinary citizens consists less in the actual research sponsored and more in the concentration of the sponsorship. For, just as the scientist's access to intellectually empowering tools should not be confused with her having any special intellectual qualities, similarly, increased institutional control over the production and distribution of scientific research should not be taken to imply that the research itself heightens the technical capabilities of the controlling institutions (MacKenzie 1990, ch. 8). On the contrary, technical capability may never be extensively tested, as appeals to "corporate secrets" and "national security" rhetorically preempt the usual scientific forms of scrutiny. As a result, even the CEOs and generals who deploy the rhetoric often have an unjustifiably optimistic sense of what the products of scientific research can do in "real life" situations.

My rejection of the citizen education solution to Big Science can thus be summarized in two points: (a) it presumes a false sense of the intellectual differences separating scientific from ordinary folks; (b) even if it presumed a correct sense of those differences, increasing the public's scientific literacy does not, by itself, open up any new opportunities for citizen participation in the conduct of science. In fact, most theories of ideology would predict that programs of scientific literacy that promise no new political outlets ultimately serve those who dominate the scientific enterprise by breaking down the cognitive barriers that prevent the citizenry from being completely comfortable with the "scientific" way of thinking. But rather than subjecting this conjecture to the scrutiny it deserves, I want to offer a positive proposal concerning the place of the critical attitude in a world where our traditional terms for knowledge fail to grasp what governs today's knowledge enterprises, which is what I mean by a post-epistemic society.

\section{An Immodest Proposal for Governing the Post-Epistemic Society}

And so, what exactly is wrong with Big Science? Lack of public accountability would seem to express the problem in its most general form, but solutions to it remain elusive. Citizen education in scientific reasoning may make science more understandable but hardly more accountable. The accountability issue can be directly addressed only if science is treated as a species of politics-though a species that retains vestiges of traditional notions of inquiry. (For example, "accountability" itself may be seen as a reformulation of the verifiability or falsifiability conditions of a knowledge claim, but now with reference to particular groups who have a stake in the validity of the claim.) The three features listed below, which characterize politics in an era of Big Democracy (Dahl 1989, chs. 15-21), would be especially conducive to accountability in an era of Big Science:

(1) Coalitions: Political theorists from Madison to Schumpeter have described the dynamics of Big Democracy as an endless "circulation of elites," by which is meant the often temporary alliances that need to be forged among disparately interested parties in order for any political program to succeed. Insofar as most scientific research today is made possible by an alignment of university, government, and corporate interests, coalition politics is al ready the implicit norm, though one that scientists are still inclined to treat as "merely expedient" and not essential to their knowledge producing functions-however much time and energy they may spend on building and maintaining such coalitions. In contrast, I would propose to make this norm explicit, by having scientists avail themselves of the media that politicians 
typically use to take their cases to the people. In short: treat research programs as party platforms. One intellectually salutary consequence of this practice would be to force scientists to reflect on the multiple ways in which various constituencies might come to have a stake in the outcome of scientific research. Moreover, as people see themselves as potential components in a scientific coalition, they are likely to become more self-conscious about the ends of knowledge production: What are the costs and benefits of pursuing one research program rather than another? This could initiate an ongoing public debate on the topic of ends, long obscured by philosophical assurances that The Truth is the end of inquiry. In any case, more broadly accessible knowledge products are likely to result, products capable of persuading a wide range of people that they were getting their money's worth.

(2) Contestation: Big Democracies are defined by their forums for managing conflict. The sudden democratization of Big Science would pose formidable problems to the public's ability to judge between competing coalitions, given both the ambivalence caused by the heterogeneous interests associated with any given coalition (e.g., military and environmental interests may be behind the same project) and the complexity of the technical issues on which the competing coalitions would differ. Under the circumstances, it is tempting simply to split the difference by allotting each side a certain amount of legal and economic space in which to do their work. However, this solution has the potential for generating still greater problems. It would discourage coalitions from thinking that they have to account to the entire population. After all, if a coalition needs only a modest plurality to receive adequate funding, why should it aim for knowledge products that would be accessible to the society at large? Unfortunately, such purely interest-based thinking runs the risk of severing accountability from responsibility for consequences that affect those outside the coalition. Thus, even if the resources were available to diversify research investments, it would be dangerous to fund a research proposal simply because it enjoyed the support of several interest groups. Rather, several such alternatives must be subject to comparative evaluation in an open forum. Instead of having the public engage with the technical details of these alternatives, competitors could confront each other through televised episodes of formal cross-examination. As the competing research proposals would often represent quite disparate fields and the television audience would range over the gamut of interests and expertises, the resulting debate would bring to light the sorts of unclarity, hyperbole, and deception that would otherwise remain hidden in the technical language of the competing proposals.

(3) Elections: Much traditional philosophical thinking about science resists the idea of periodic elections in which the fortunes of research programs can be substantially reversed. The importance of elections in Big Democracy testifies to the reversibility of all political programs. Big Science, by contrast, remains fixated on the image of inquiry as proceeding by a natural trajectory, unless subject to interference. Admittedly, philosophers frequently reconstruct the history of science as a series of "theory choice" episodes, in which one of the options constitutes a radical departure from the reigning orthodoxy. However, on most accounts, even the radical successor must approximately save the phenomena of its conservative forebear, thereby suggesting continuity at least in the data that need to be explained. This sense of continuity is re inforced by the idea that the primary aim of science is The Truth, which, in turn, has tended to reduce normative questions about inquiry to disputes over the appropriate means to this already agreed upon end. It is no accident that the philosophy of science has been primarily concerned with something called "methodology" rather than "axiology" (an exception is Laudan 1984). The same continuity may be detected in the narrative structure of research 
grant proposals, which stress a path of increasing specialization and elaboration in the solution of persistent theoretical problems. And, even when sociologists of science have doubted this narrative's adequacy to actual scientific practice, they have typically replaced it with another tale of continuity, often one that depicts scientific progress as being driven by the need to exploit the investigative potential of expensive laboratory equipment. Big Science is most perilous when any of these continuity arguments and stories are taken to underwrite what might be called "techno-fatalism," the idea that science must proceed either in its current state or not at all. By requiring that ongoing projects account for themselves on a regular basis, science elections would enable alternative coalitions to propose novel ways of configuring available intellectual and material resources.

The most utopian feature of the above tripartite scheme is its assumption that citizens in Big Democracy are already sufficiently engaged in politics to be able to add scientific research as one more issue around which coalitions can be formed and elections fought. Unfortunately, nothing could be farther from the truth (cf. Dahl 1989, Yankelovich 1991). Indeed, I would argue that the biggest obstacle facing Big Science's public accountability is not lack of competence but lack of interest. After all, there is an arena in which the public has no difficulty evaluating an intaglio of complex rules and skilled performances, following running commentaries and statistical indicators abstracted from those performances, and identifying its own fate with possible outcomes-even to the point of regularly betting on those outcomes when permitted. That arena, of course, is sports.

The fact that people around the world can intelligently engage with sporting events yet increasingly fail to be galvanized by democratic politics highlights the extent to which traditional philosophical fears about the prospect of "socialized knowledge" have been seriously misplaced. Recalling the worst nightmares of "proletarian science" deployed during the Cold War, philosophers often act as if Big Science needs to be protected from a public that is all too eager to get its hands on the research agenda-a public that could do irreparable damage to that agenda, were it so commandeered. This perhaps explains why those epistemologists who have been most receptive to a social characterization of knowledge have also been interested in promoting the doctrine of epistemic "expertism" (Stich \& Nisbett 1984) or "paternalism" (Goldman 1991) in order to provide rational grounds for the lay public deferring to scientists' judgments under normal circumstances (cf. Fuller 1988, ch. 12). Once again, my response is that these safeguards are beside the point, insofar as people are already unwittingly disposed to follow such philosophical advice-but more out of boredom with anything political (especially science) than out of any admission to their cognitive shortcomings.

In short, transcending the utopian status of my proposal would involve importing to science the sorts of things that make sports so compelling for so much of the world's population. Indeed, I am tempted to reduce the challenge here to one of getting people sufficiently interested in the conduct of science that they are driven to increase their stake in it. That is one of the few ways to tell that people are engaged with the fate of an enterprise. Here I follow a long line of subjective probability theorists (esp. Frank Ramsey and John Maynard Keynes) who measure the strength of one's belief by one's willingness to bet on the belief being true (for historical background, see Hacking 1975 , Daston 1987). But, clearly, with the exception of pathological gamblers, people are quite selective about what they are willing to place bets on. Sporting events typically have three features that make them especially attractive to "rational gamblers." These features are notoriously lacking 
from the scientific enterprise-not to mention, politics more generally:

(1) An easily accessible canonical accounting procedure: Just as daily newspapers run statistical breakdowns of all the teams in a sports league, one could imagine similar data-perhaps more along the lines of a "Consumer"s Reports"- regularly gathered and published on the officially recognized coalitions, component interest groups, level of support, current projects, and output to date as some function of input. Potential bettors would thus have a clear sense of the affiliations and track records of the contestants. For, as it stands now, even the federal government must struggle to figure out the nature and level of research support in the private sector, as well as to prevent missed opportunities and overkill from happening in the public sector (cf. Chubin 1991). While intellectual property law-patents, copyrights, and trademarks-does a reasonable job of registering and policing (though, not publicizing) completed knowledge products and processes, a comparable system for "works in progress" has yet to be developed.

(2) Fair and explicit rules of the game: As people have increasingly come to realize the mythic character of "cognitive norms" and "methods of science," a common response has been to become mystified and ultimately disengaged from the conduct of science. Thus, the public continues to marvel at the latest breakthroughs in research, but very much in the manner of an entertaining fiction that operates in ways that cannot be fully fathomed without destroying the illusion (cf. Postman 1986). In this sense, the demystification of method has led to a decline in the public scrutiny of science, as scientists retreat behind the special effects produced by their technical expertise. The remedy is to provide incentives for scientific coalitions to challenge each other in an open forum. For example, one coalition may bet part of its research budget that it can achieve its goals before another coalition achieves theirs. Targets may be chosen strategically, so that a coalition behind an upstart molecular biology program may challenge a long-standing program in nuclear physics that is beginning to exhibit diminishing returns on investment. Contests featuring such orthogonal foes would help accustom the public to comparing the research potential and products of different disciplines, especially as they try to decide where to place their own bets. Notice that the type of contest described here bears a closer resemblance to boxing than to baseball, in that the occasions for a contest are determined, not by a schedule set independently of the degree of interest in the contest but, rath$\mathrm{er}$, by parties sufficiently interested in mounting a challenge that the size of their wager attracts the champion into the ring.

(3) Something worth contesting: This is perhaps the only condition that makes politics more publicly scrutable and more attractive to gamblers than science. Nevertheless, the condition is a significant one. It raises the general question of which features of science are worth betting on. If we envisage that research programs covering quite different fields can challenge one another, then among the more fruitful debates would be one over which program is more likely to generate the more desirable knowledge products, given the resources at stake. Philosophers of science should recognize this strategy as involving the "context of pursuit" (Laudan 1981) and "heuristic appraisal" (Nickles 1989). Stock brokers call it, quite aptly, "speculating on futures" (cf. Hanson 1990). The two sides could cross-examine each other about their track records, subject to the sort of procedural rules that a judge typically monitors in the courtroom. One side may succeed in showing that the other side did not deserve credit for part of the track record that it now wants to use to justify its claim to resources. Presumably, this would disincline people from betting on that side in the future, perhaps leading to the breakup of the coalition that had so far supported that side. 
The reader will notice that my proposal makes at least three quite controversial assumptions, the basis for which will have to await another paper. First, I presume that the procedures governing scientific contests can be made sufficiently transparentperhaps even scored on points-that the judgments of the referees and the viewing public will coincide on most occasions, just as they do in sports. Thus, after one such contest, there should be a straightforward way of establishing the winner. I believe that the intuitive implausibility of this prospect merely testifies to the public's current alienation from the scientific enterprise. Second, I presume that science elections can be highly adversarial without turning into a zero-sum game, in which the contestants (and their supporters) feel that there is no middle ground between vanquishing and being vanquished. My response here would be to empower the judiciary with holding research teams responsible for the consequences of their actions (including the ease with which they make their products available to others). Even when the consequences are irreversible, the victims may nevertheless be compensated. Proposals of this sort are already being discussed by lawyers concerned about the decisive role that "false science" often plays in underwriting risk assessments (Huber 1991). Third, and finally, who collects the bets, who distributes them, and by what principle?

\section{References}

Bazerman, C. (1988) Shaping Written Knowledge. Madison: University of Wisconsin Press.

Bourdieu, P. (1975) "The Specificity of the Scientific Field and the Social Conditions of the Progress of Reason." Social Science Information $14(6): 19-47$.

Chubin, D., et al. (1991) Federally Funded Research: Decisions for a Decade. US Government Printing Office: Office of Technology Assessment.

Clark, N. (1985) The Political Economy of Science and Technology. Oxford: Blackwell.

Cohen, L.J. (1981) "Can Human Irrationality Be Experimentally Demonstrated?" Behavioral and Brain Sciences 4:317-331.

Collins, H. (1990) Artificial Experts. Cambridge MA: MIT Press.

Coulter, J. (1983) Rethinking Cognitive Theory. London: Macmillan.

Dahl, R. (1989) Democracy and Its Critics. New Haven: Yale University Press.

Daston, L. (1987) Classical Probability in the Enlightenment. Princeton: Princeton University Press.

Dolby, R.G.A. and Cherry, C. (1989) "Symposium on the Possibility of Computers Becoming Persons." Social Epistemology 3:321-348.
Etzkowitz, H. (1989) "Entrepreneurial Science in the Academy." Social Problems 36:14-29.

Faust, D. (1984) The Limits of Scientific Reasoning. Minneapolis: University of Minnesota Press.

Feyerabend, P. (1975) Against Method. London: Verso,

Feyerabend, P. (1979) Science in a Free Society. London: Verso.

Fuller, S. (1988) Social Epistemology. Bloomington: Indiana University Press.

Fuller, S. (1989) Philosophy of Science and Its Discontents. Boulder: Westview Press.

Fuller, S. (1992a) "Epistemology Radically Naturalized: Recovering the Experimental, the Normative, and the Social." In R. Giere (ed.) Cognitive Models of Science, Minnesota Studies in the Philosophy of Science, Vol. 15. Minneapolis: University of Minnesota Press.

Fuller, S. (1992b) "Social Epistemology and the Research Agenda of Science Studies." In A. Pickering (ed.) Science as Practice and Culture. Chicago: University of Chicago Press.

Fuller, S. and Gorman, D. (1987) "Burning Libraries." Annals of Scholarship 4,3.

Gergen, K. (1985) Towards a Transformation of Social Knowledge. Amsterdam: Elsevier. 
Gergen, K. and Gergen, M. (1982) "Explaining Human Conduct: Form and Function." In P. Secord (ed.) Explaining Human Behavior. Beverly Hills: Sage.

Gilbert, N. and Mulkay, M. (1984) Opening Pandora's Box. Cambridge, UK: Cambridge University Press.

Goldman, A. (1991) "Epistemic Paternalism." Journal of Philosophy 88 (March).

Goldman, A. and Shaked, M. (1991) "An Economic Model of Scientific Activity." Philosophical Studies. 63:31-55.

Hacking, 1. (1975) The Emergence of Probability. Cambridge, UK: Cambridge University Press.

Hanson, R. (1990) "Could Gambling Save Science?" Proceedings of the Eighth International Conference on Risk and Gambling. London. (A symposium version will appear in Social Epistemology.)

Hewstone, M. (1989) Causal Attribution. Oxford: Blackwell.

Huber, P. (1991) Galileo's Revenge. New York: Basic Books.

Kevles, D. (1987) The Physicists. 2nd ed. Berkeley: University of California Press.

Kitcher, P. (1990) "The Division of Cognitive Labor." Journal of Philosophy 87:5-22.

Knorr-Cetina, K. and Cicourel, A. (eds.) (1981) Advances in Social Theory. London: Routledge \& Kegan Paul.

Latour, B. (1987) Science in Action. Milton Keynes: Open University Press.

Latour, B. and Woolgar, S. (1979) Laboratory Life. Beverly Hills: Sage.

Laudan, L. (1981) "A Problem-Solving Approach to Scientific Progress." In I. Hacking (ed.) Scientific Revolutions. Oxford: Oxford University Press.

Laudan, L. (1984) Science and Values. Berkeley: University of California Press.

MacKenzie, D. (1990) Inventing Accuracy. Cambridge, MA: MIT Press.

McCloskey, D. (1987) Economic Writing. London: Macmillan.

Mukerji, C. (1990) A Fragile Power. Princeton: Princeton University Press.

Mulkay, M. (1990) The Sociology of Science. Bloomington: Indiana University Press.

Nickles, T. (1989) "Heuristic Appraisal: A Proposal." Social Epistemology. 3:175-188.
Nisbett, R. and Wilson, T. (1977) "Telling More Than We Can Know." Psychological Review 84: $231-259$.

Noble, D. (1984) Forces of Production. Oxford: Oxford University Press.

Postman, N. (1986) Amusing Ourselves to Death. Harmondsworth, UK: Penguin.

Price, D. (1964) Little Science, Big Science. Harmondsworth, UK: Penguin.

Rescher, N. (1978) Peirce's Philosophy of Science. South Bend: Notre Dame Press.

Rescher, N. (1979) Scientific Progress. Oxford: Blackwell.

Rescher, N. (1984) The Limits of Science. Berkeley: University of California Press.

Rorty, R. (1988) "Is Natural Science a Natural Kind?' In E. McMullin (ed.) Construction and Constraint. South Bend: Notre Dame Press, pp. 49-74.

Ross, L. (1977) "The Intuitive Psychologist and his Shortcomings." In L. Berkowitz (ed.) Advances in Experimental Social Psychology. New York: Academic Press.

Shapin, S. (1988) "The House of Experiment in Seventeenth Century England." Isis 79:373-404.

Slezak, P. (1989) "Scientific Discovery by Computer as Empirical Refutation of the Strong Programme." Social Studies of Science. 19:563-600.

Stich, S. and Nisbett, R. (1984) "Expertise, Justification, and the Psychology of Inductive Inference." In T. Haskell (ed.) The Authority of Experts, Bloomington; Indiana University Press, pp. 226-241.

Thagard, P. (1988) The Computational Philoso phy of Science. Cambridge, MA: MIT Press.

Turner, S. and Turner, J. (1990) The Impossible Science. Newbury Park, CA: Sage.

Unger, R. (1986) The Critical Legal Studies Movement. Cambridge, MA: Harvard University Press.

Woolgar, S. (1988) Science: The Very Idea. London: Tavistock.

Yankelovich, D. (1991) Coming to Public Judgment, Syracuse: Syracuse University Press. 